\title{
The airborne identification of oil films at the Caspian sea surface using $\mathrm{CO}_{2}$ lidar
}

\author{
Vladimir U. OSADCHY a ${ }^{\text {, Kusiel S. SHIFRIN }}{ }^{\text {b*, Irina Ya GUREVICH }}{ }^{\text {a }}$ \\ ${ }^{\text {a }}$ St Petersburg Department, Institute of Oceanology, Acad. Science RAN, Tavricheskay Street 11, 193015 St Petersburg, \\ Russia \\ ${ }^{\mathrm{b}}$ College of Oceanic and Atmospheric Sciences, Oregon State University, 104 Ocean Adm. Bldg, Corvallis, OR 97331- \\ 5503,USA. shifrink@ucs.orst.edu
}

(Received 17 October 1997, revised 27 May 1998, accepted 2 July 1998)

\begin{abstract}
Contrast in the reflectivity between pure and contaminated sea surfaces is the result of two effects, namely: (1) the different reflectivity of sea water and oil films on sea water, and (2) the damping effect by the oil film on the sea waves. The problem is to estimate the contribution of these two effects on the total contrast, so that the substance effect can be calculated. Magnitude is related to the oil film thickness. The spectral behaviour of the contrast and its relationship with the film thickness were calculated for an undisturbed sea surface. The estimate of the damping effect was made using the Cox and Munk's slope distributions for pure and contaminated surfaces. The method chosen was verified by a series of tests conducted over the Caspian Sea from an aircraft carrying a $\mathrm{CO}_{2}$ laser sensor operating at $10.6 \mu \mathrm{m}$. $\odot$ Elsevier, Paris $/$ Ifremer / Cnrs / Ird
\end{abstract}

\section{oil / optical constant / pollution / sea surface / remote sensing}

Résumé - Télédétection des nappes d'hydrocarbures à la surface de la mer Caspienne par lidar à $\mathrm{CO}_{2}$. Le contraste entre la réflectivité d'une surface d'eau pure et celle d'une eau polluée a deux origines : 1) réflectivités différentes de l'eau de mer et de l'huile ; 2) amortissement des vagues par le film d'huile. Il faut donc estimer la contribution de chacun de ces phénomènes dans le contraste eau-huile afin de calculer l'effet de l'huile. L'importance du contraste est proportionnelle à l'épaisseur de la nappe d'huile ; sa répartition spectrale et sa relation avec l'épaisseur du film sont déterminées dans le cas d'une mer calme. L'amortissement des vagues est estimé en utilisant la distribution des pentes proposée par Cox et Munk pour des eaux pures et polluées. La méthode a été appliquée à la mer Caspienne dans une série de mesures par télédétection à l'aide d'un lidar à $\mathrm{CO}_{2}$, à la longueur d'onde 10,6 $\mu \mathrm{m}$. $\odot$ Elsevier, Paris / Ifremer / Cnrs / Ird

\section{hydrocarbure / caractéristique optique / pollution / surface de la mer / télédétection}

\section{INTRODUCTION}

\subsection{The fundamentals of the theory}

The difference in reflectivities of contaminated and pure areas of the sea surface is the result of two effects, namely, (1) the difference of reflectivity of sea water and oil films on water, the so-called "substance effect", and (2) the damping effect of the oil film on sea waves, causing a change in surface roughness [2].
The main problem in interpreting optical remote sensing results is estimating the separate contributions of the two effects to the total contrast, so that both effects can be isolated.

In this work, we calculate the difference between oil slicks and pure sea surface optical properties; we perform real sea measurements of contrasts on the Caspian Sea and investigate the possibility of measuring the oil film thickness by means of $\mathrm{CO}_{2}$ Laser.

* Correspondence and reprints 
First, we consider the simplest case; that of light normally incident on a flat film covering calm water. Our aim is to determine the dependence of the contrast $K$ on the physical properties of oil, and to reveal the spectral intervals of high contrast. The contrast may be defined as:

$K(1 \gamma)=\frac{R_{2,3}(1 \gamma)-R_{1,3}(\lambda)}{R_{2,3}(1, \lambda)}$

where $\lambda$ is the radiation wavelength; $\rightarrow 1$ is the oil film thickness; where the subscripts 1,2 and 3 correspond to water, oil and air respectively, $R_{2,3}$ is the energy reflectance coefficient at the oil-air boundary, and $R_{1,3}$ is that for the air-water boundary. The reflection coefficient for the electromagnetic field is found as: (see [2] §1.6)

$$
V_{2,3}=\frac{\left(m_{2}+1\right)\left(1-m_{2}\right)+\left(m_{2}-1\right)\left(1+m_{2}\right) e^{-4 \pi x m_{2}}}{\left(m_{2}+1\right)\left(1+m_{2}\right)+\left(m_{2}-1\right)\left(1-m_{2}\right) e^{-4 \pi x m_{2}}}
$$

Here $m=n-i \mathrm{~K}$ is the complex refractive index of the medium ( $n$ and $\kappa$ are the refraction and absorption indices). We take into account that for air $m_{3}=1$ and we use the relative film thickness $x=\frac{1}{\lambda}$.

The reflection coefficient for the intensity is:

$$
R_{2,3}=\left|V_{2,3}\right|^{2}
$$

We used optical constants $n$ and $x$ for the ultra-violet (UV), visible (VIS) and infrared (IR) regions obtained for sixteen oil samples of different oil fields and wells and for one diesel fuel sample $[1,11]$. The typical behaviour of $n$ and $\kappa$ for sea water and oil is shown in [10, figure 3,8$]$.

The meaning of $n$ and $\kappa$ is indicated in [2]. There is great dispersion of $\kappa$ for oils of different origins. The behaviour of the dispersion of the oil optical constants is shown in figures $l a$ and $l b$. The variance presented in figure $l$ gives an indication of how quantities used in the present study would vary if one kind of oil were substituted for another. For this simplest case the reflection coefficients have been calculated using (3). In practically all of the spectral ranges considered, the oil is brighter than the water. Contrast is strongly influenced by the spectral behaviour of the reflection coefficient $R_{1,3}$ of sea water because $R_{2,3}$ of oil changes slightly whereas $R_{1,3}$ changes significantly.

Formula (3) has been used to calculate the dependence of the reflection coefficient for the intensity on the oil film thickness $[4,5]$. The calculations were performed for twenty wavelengths within the $0.3-15 \mu \mathrm{m}$ spectral range.
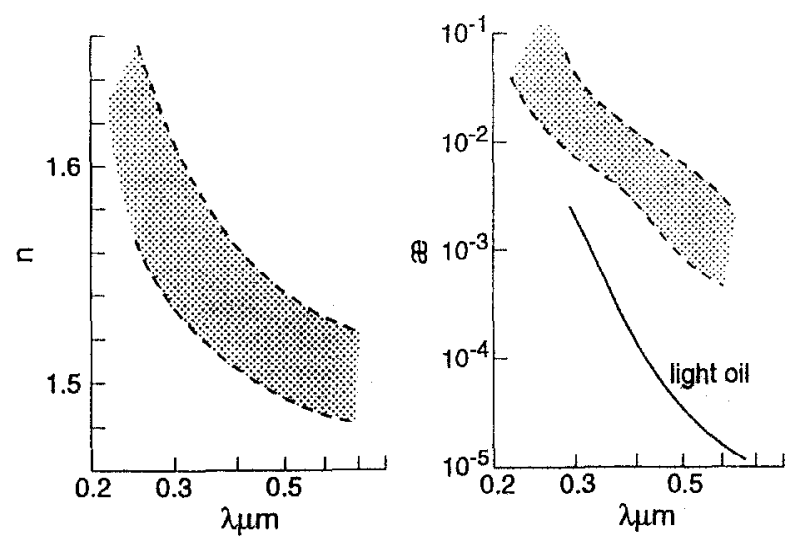

(a)
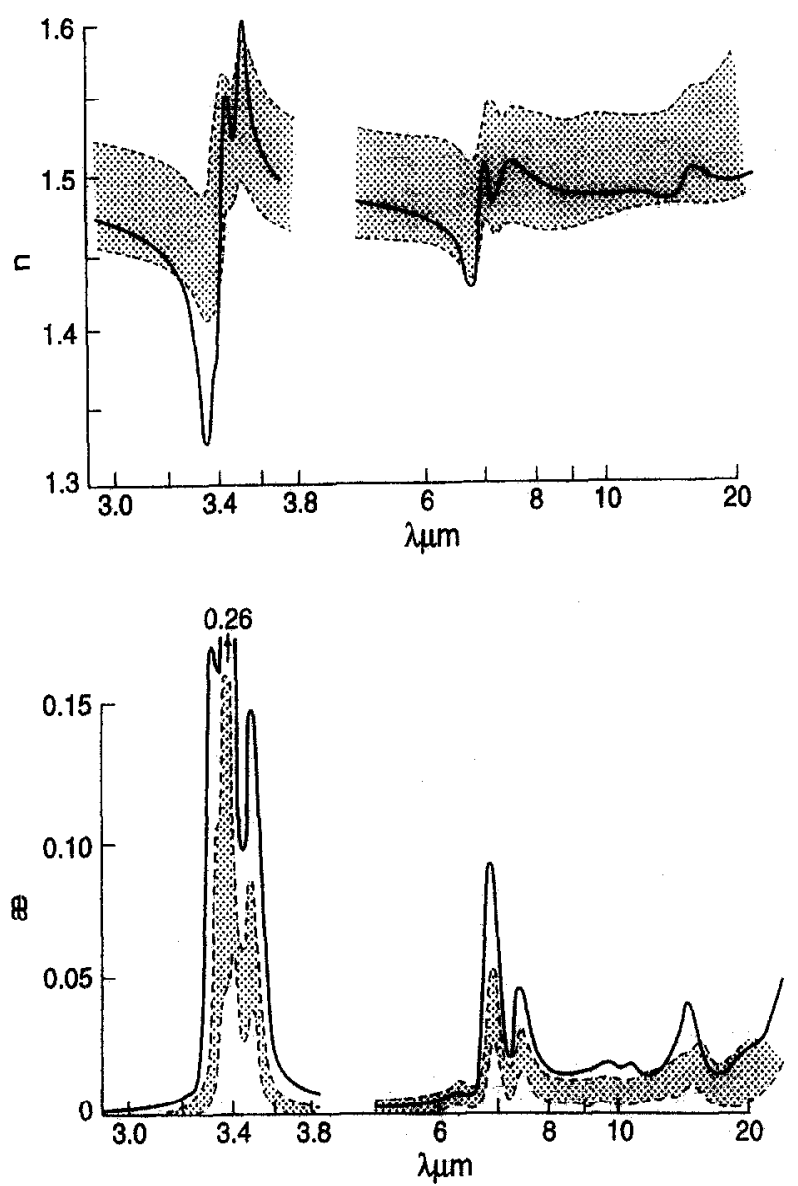

(b)

Figure 1(a). Dispersion of the optical constants of oils from fourteen different oil fields in the spectral range of $0.2-0.6 \mu \mathrm{m}$; left: dispersion of $n$; right: dispersion of $\kappa$. (b) Dispersion of the refraction index of the same oils presented on figure $l(a)$ for the infrared range of the spectrum. The solid curve is for diesel fuel. 
In real sea conditions, the oil film thickness becomes randomly distributed within a contaminated area. Optical sensors have a finite view field and averaging time and so their response is the result of the interaction of light with the oil film, with the thickness randomly distributed within the sensor view field. This response can be calculated provided the thickness distribution of the oil film is known.

In order to obtain estimates of the influence of the oil film thickness distribution on the remote sensor response, some plausible assumptions had to be made about the distribution law.

We assumed that this distribution has a form of gamma distribution (its properties are described, for example, in [10]). For the gamma distribution $f^{*}(x)$ having the parameter $\mu$,

$f^{*}(x)=C_{\mu} x^{\mu} \exp \left[-\frac{\mu+1}{\bar{x}} x\right]$,

where $C_{\mu}$ is a constant factor and $\bar{x}=\frac{\dot{I}}{\lambda}$.

The response of the monochromatic light receiver is defined by:

$W_{2,3}(\bar{x})=\int_{0}^{\infty} R_{2,3}(x) f^{*}(x) d x$.

$R_{2,3}(x)$ is the reflection coefficient of a flat film of relative thickness $x$. Dependences of $W_{2,3}$ on the mean relative film thickness $\bar{x}$ have been calculated for ten values of parameter $\mu: \infty, 24,18,12,6,4,3,2,1,0$, corresponding to the variance from zero to the maximum possible magnitude for this distribution law. The calculations have been made for four wavelengths corresponding to the known lasers: $\lambda=0.63 \mu \mathrm{m}$ (He-Ne laser); $\lambda=3.40 \mu \mathrm{m}$ (Ne laser); $\lambda=5.40 \mu \mathrm{m}$ (Ne laser); $\lambda=10.6 \mu \mathrm{m}\left(\mathrm{CO}_{2}\right.$ laser). Qualitatively, the results of the calculations for different wavelengths are quite similar, so we only show here the dependence of $W_{2.3}$ on $\bar{x}$ for $\mathrm{l}=10.6 \mu \mathrm{m}$ with different values of $\mu$ (figure 2). For all wavelengths, $W_{2,3}$ shows a series of fading oscillations. The intensity of the fading increases with increasing distribution width. For a wide distribution, only the first maximum $W_{2,3}\left(x_{m}\right)$ is present. The position of this maximum $x_{m}$ is equal to that of a monodispersed film. For wide distributions we found:

$W_{2,3}\left(x_{m}\right)=33.2 \cdot R_{2,3}^{2}$
Eq. (6) yields values of the integral in (5) with an accuracy of $10 \%$ which appears to be satisfactory. Unfortunately, the strong influence of the shape of the distribution of the oil film thickness on the sensor response limits the possibility of remote measurements of oil film thickness (using, for example, the laser-induced fluorescence technique [6]).

For the calculations of the reflection from the wavy sea surface we considered the distribution of facet orientations taken from $[3,7]$. For backward reflection, the polarisation state of light does not change and thus we shall consider only the radiance $B_{1}$. For this case $[3,7]$ we have:

$B_{1}=\frac{1}{4} \sec ^{2} \theta P\left(\theta_{n}, \varphi_{n}\right) R E_{\mathrm{o}}$

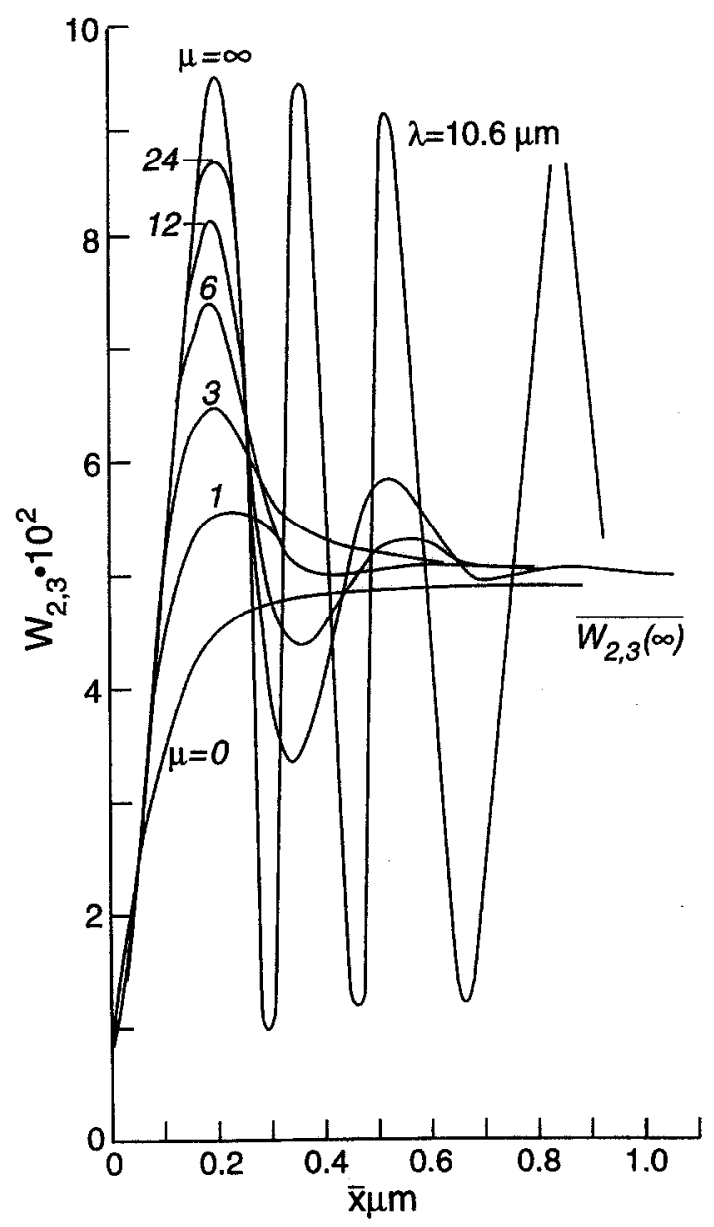

Figure 2. Dependence of the reflection coefficient on the mean oil film thickness for different widths (different parameter $\mu$ ) of distribution of the oil film thickness for $\lambda=10.6 \mu \mathrm{m}$ and $v=10 \mathrm{~m} \mathrm{~s}^{-1}$. 
where $P\left(\theta_{n}, \varphi_{n}\right)$ is the number of horizontal facets per square unit; $R$ is the reflection coefficient of a facet and $E_{0}$ is its irradiance.

The lidar cross-section B is defined as the ratio between the radiance of light reflected in the direction of the source and the radiance of an ideal scatterer in similar illumination conditions. The ideal scatterer radiance is $B_{s c}=E_{0} / \pi$ we have:

$B=\frac{B_{1}}{B_{s c}}=\frac{\pi}{4} \sec ^{2} \theta P\left(\theta_{n}, \varphi_{n}\right) R$

The results of the calculations of $B$ for different $\theta$ for pure and oiled sea surfaces are presented in figure 3. It was considered that the dispersion $\sigma^{2}$ of the distribution $P\left(\theta_{n}, \varphi_{n}\right)$ for an oiled surface was smaller than $\sigma^{2}$ for a pure surface by about a factor of three [3] (damping effect). It follows from figure 3 that for the direction of sensing at nadir $\left(\theta=0^{\circ}\right)$, the lidar cross-section decreases as the wind speed $v$ increases for both oiled and pure surfaces, because the reflectivity becomes more diffusive. But, independently of wind speed, the lidar cross-section for an oiled surface is greater than that for the pure surface for this direction. This is the result of the two effects described above.

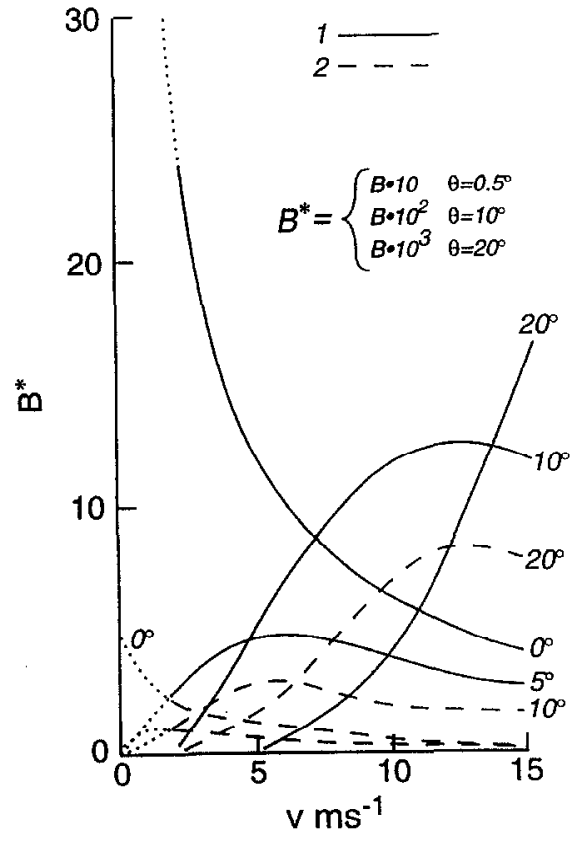

Figure 3. Dependence of the magnitude of the lidar cross-section on the wind speed for the pure and oiled sea surface for different sensing directions $\theta=0,5,10,20^{\circ}: 1$ ) oiled sea surface; 2) pure sea surface.
For $\left(\theta \neq 0^{\circ}\right)$, the function $B(v)$ presents a maximum. This can be well observed in figure 5 . Since oil damps waves, the number of facets of an oiled surface is less than that for a pure surface. For small values of $v$, the contrast between contaminated and pure surfaces becomes negative. For any fixed $\theta$, the value of $v$ corresponding to the maximum of $B(v)$ can be determined. The behaviour of $B(v, \theta)$ is significant for the purpose of remote sensing of oil films by scanning systems.

Figure 4 shows the spectral behaviour of the contrasts $K$ of the lidar cross-sections for pure and contaminated sea surfaces for $\theta=0^{\circ}, 5^{\circ}, 10^{\circ}$ and $v=10 \mathrm{~m} \mathrm{~s}^{-1}$.

It is significant that the interval of the contrast $\approx 0$ exists in the vicinity of $\lambda=3.4 \mu \mathrm{m}$ for $K_{0}$ and for $K$ at $\theta=10^{\circ}$, while for $v=10 \mathrm{~m} \mathrm{~s}^{-1}$ and $\theta=0.5^{\circ}$ there is no interval of zero contrast for $K\left(K_{0}\right.$ is the contrast between plane water and oil surfaces). Thus, if the contrast is measured using $\lambda=3.4 \mu \mathrm{m}$ only information on the effect of damping waves will be obtained. If we want to separate the two effects determining the contrast, we must use a twowavelength lidar including the obligatory wavelength $\lambda \approx 3.4 \mu \mathrm{m}$. Such a separation is of primary importance when measuring the oil film thickness.

\section{RESULTS}

The measurement parameters presented in the table $I$ ensure airborne observations at altitudes up to $500 \mathrm{~m}$. It is

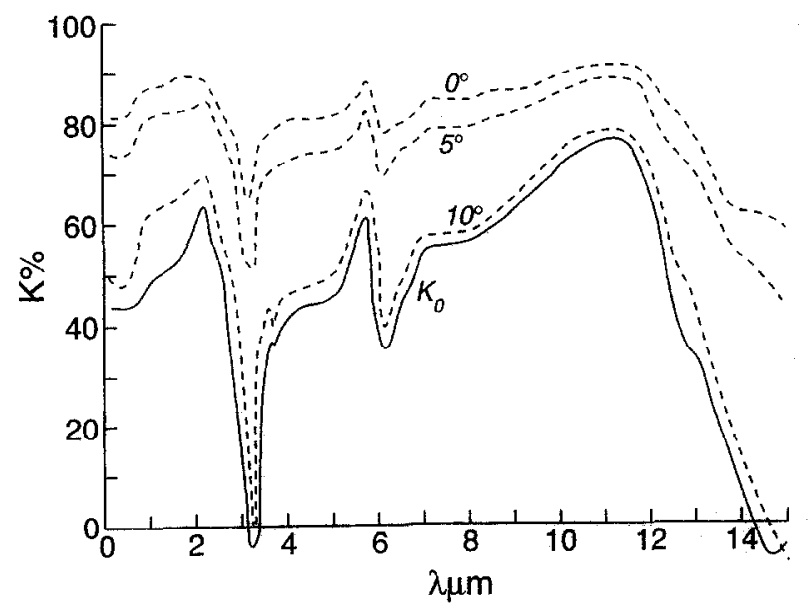

Figure 4. The contrast of lidar cross-sections $K$ for different directions of sensing $\theta=0^{\circ}, 5^{\circ}, 10^{\circ}$ for the wind speed $v=10 \mathrm{~m} \mathrm{~s}^{-1}$. 
Table I. Measurement parameters used in airborne observations.

\begin{tabular}{lc}
\hline Average power of a $\mathrm{CO}_{2}$ laser & not less than $4 \mathrm{~W}$ \\
Laser beam angle & $0^{\circ} .5$ \\
Mirror diameter of receiving telescope & $400 \mathrm{~mm}$ \\
Threshold sensitivity of pyroelectric receiver & $10^{-2} \mathrm{~W}$ \\
$\begin{array}{l}\text { Average time necessary for registering } \\
\text { the return signal }\end{array}$ & 0.5 or $1 \mathrm{~s}$ \\
\hline
\end{tabular}

known that the output of $\mathrm{CO}_{2}$ lidar contains many longitudinal modes. Since they have similar wavelengths, the optical constants for oil and sea water are similar for all modes. Because of this, the polymodality of radiation does not affect the film contrast. It can be of importance when estimating the maximum flight altitude where it is still possible to carry out measurements.

For an aircraft speed of $100 \mathrm{~m} \mathrm{~s}^{-1}$ (typical for the IL-14 airplane used in our experiments), a flight altitude of $200 \mathrm{~m}$ and an averaging time of recording of the lidar response of $1 \mathrm{~s}$, the area of averaging related to the sea surface is equal to $170 \mathrm{~m}^{2}$. This value may be considered high enough to make it possible to determine the sea slope distribution function.

In order to obtain more accurate estimates of the contribution to the contrast of the effects of substance and damping waves, it is more appropriate to use the ratio $R_{\text {rel }}=\frac{W_{2,3}}{W_{1,3}}$ as a measure of contrast rather than the conventional formula (1). The relation between $R_{\text {rel }}$ and $K$ is: $R_{\mathrm{rel}}=1 /(1-K)=\frac{R_{2,3}}{R_{1,3}}($ see $(1))$. This implies that $\frac{W_{2,3}}{W_{1,3}}=\frac{R_{2,3}}{R_{1,3}}$.

$R_{\text {rel }}=\frac{\bar{R}_{2,3}}{R_{1,3} \int_{\Omega} \int_{\Omega} P_{2,3} d \omega}$

up to a constant factor.

Here, $\bar{R}_{2,3} / R_{1,3}$ is the ratio of reflection coefficients of the oil film and pure water giving a measure of the substance effect and $\bar{P}_{2,3} / \bar{P}_{1,3}=\frac{\int_{\Omega} P_{2,3} d \omega}{\int_{\Omega} P_{1,3} d \omega}$ provides a measure of the effect of damping waves.
$P_{2,3}$ is the sea slope distribution function for the contaminated surface, and $P_{1,3}$ is that for the pure sea surface; $d \omega$ is an element of solid angle. Integration limits $\Omega$ are determined by the angular width of the laser beam, the field of view of the receiving optical system and the direction of sensing.

The majority of experimental data were obtained over oil fields on the Caspian Sea near the city of Baku. The optico-mechanical unit of the lidar was mounted in the photo-hatch of an IL-14 airplane with a flight speed of $70-100 \mathrm{~m} \mathrm{~s}^{-1}$ during the experiments $[8,9]$.

Flights were chosen so as to obtain records of the lidar response from the pure sea surface and then, after crossing the oil slick boundary, from the contaminated surface. The usual flight altitude was $200 \mathrm{~m}$ and the averaging time $1 \mathrm{~s}$. In some cases, measurements were made from different altitudes (from 50 to $500 \mathrm{~m}$ ) with averaging times $0.5 \mathrm{~s}$ and $1 \mathrm{~s}$ over one and the same oil slick in order to change the area of averaging.

There were many cases with vast oil slicks providing record durations of tens of seconds and even longer. In order to illustrate the experimental results, we have chosen results obtained in two very clear cases: (1) sensing of a vast obviously optically thick film and (2) sensing of a film formed by oil oozing out of an isolated underwater source.

For the optically thick film, data were obtained in a series of flights during one day from four different altitudes from 50 to $200 \mathrm{~m}$ over the same oil slick. The wind speed was about $10 \mathrm{~m} \mathrm{~s}^{-1}$. The sensing direction was at nadir. For all flights over the slick, the measured ratio $R_{\text {rel }}$ was approximately equal to 35 . Since $\bar{R}_{2,3} / \bar{R}_{1,3} \varphi 5$ for the $10 \mu \mathrm{m}$ wavelength, $\bar{P}_{2,3} / \bar{P}_{1,3} \varphi 7$. This value is significantly greater than the estimate obtained using the data in [6, Eq. (9)]. This fact can be explained by the assumption of a change in the shape of the sea slope distribution law for the contaminated sea surface area.

The flights over an isolated underwater source of oil (derelict underwater bore-hole) were performed in moderate wind-wave conditions (the wind speed was in the range of $2-3 \mathrm{~m} \mathrm{~s}^{-1}$ ) making the picture of oil spreading rather simple.

The survey of the oil slick is represented in the middle part of figure 5. In the upper part of the figure, a copy of a record of the lidar response is shown demonstrating the dependence of $W_{2,3}$ on the distance $\mathrm{L}$ from the source $\mathrm{S}$ along the flight direction. Along the $600 \mathrm{~m}$ of the path A- 


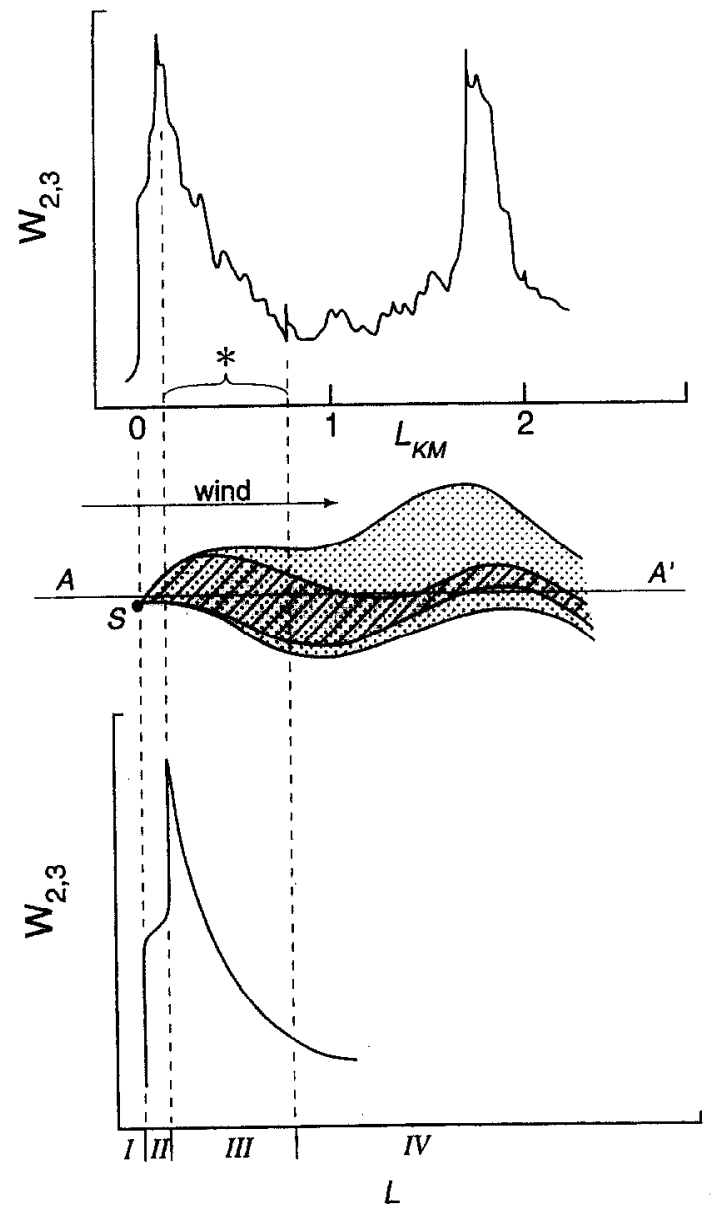

Figure 5. Schematic representation of flights over an isolated oil source and a copy of a lidar response record.
$\mathrm{A}^{\prime}$ marked by the asterisked braces, the dependence of the film thickness on $L$ can be approximated by $\mathrm{ZL}$. This is explained by the fact that in the early stages of spreading, the slick width is proportional to $\mathrm{L}$.

The variations of $W_{2,3}$ appeared to be quite similar: $W_{2.3} \sim 1 / \mathrm{L}$ demonstrating a good correlation between $W_{2.3}$ and $I$ The range of oil thicknesses along the first $600 \mathrm{~m}$ of the path $\mathrm{A}-\mathrm{A}^{\prime}$ can be estimated as $2 \pm 0.1 \mu \mathrm{m}$. These values are quite usual for tails of large oil slicks in warm sea water.

The behaviour of oil in the slick and the corresponding changes of the lidar response can be explained with the help of the schematic picture represented in the lower part of figure 5. Four sections can be picked out on the path $\mathrm{A}-\mathrm{A}^{\prime}$ and on the schematic copy of the lidar response record. Section I corresponds to the uncontaminated sea surface. Section II corresponds to the area of an optically thick film generated by oil running out of the bore-hole. At the boundary point between sections II and III, the oil film thickness reaches the value corresponding to the first maximum of the dependence of the oil film thickness on wavelength. Section III corresponds to the area of the oil thickness change according to the law $1 / \mathrm{L}$, and section IV corresponds to the area of twisting of the oil slick by a local surface current.

The exposed data show the possibility of measuring oil thickness in the interval of thicknesses of $0.1-2 \mu \mathrm{m}$ using $\mathrm{CO}_{2}$ lidar. The areas of oil films with such thicknesses could be selected by some additional means.

\section{REFERENCES}

[1] Alperovich L.I., Komarova A.I., Narzyiev B.P., Pushkarev V.N., Optical constants of oil in the region of $0.25-0.25 \mu \mathrm{m}$. Zhurnal prikladnoy spektroskopii 28 (4) (1978).

[2] Born M., Wolf E., Principles of Optics, 6th ed., Pergamon, New York, 1991

[3] Cox C., Munk W.H., Slopes of the sea surface deduced from photographs of sun glitter, Scripps Inst. Oceanogr. Bull. 6 (9) (1956) $401-479$

[4] Gurevich, I.Ya., Shifrin K.S., Reflection of visual and infrared radiation by oil films on the sea, Optical methods used in the study of oceans and internal reservoirs, Nauka Publ., Novosibirsk, 1979, pp. 166-183 (in Russian).

[5] Gurevich I.Ya., Kokorin A.M., Shifrin K.S., Reflection of optical emission by oil films of variable thickness, Okeanologiya 22(4) (1982).
[6] Hoge F.E., Oil film thickness using airborne laser-induced oil fluorescence backscatter, Applied Optics 22 (21) (1983).

[7] Mullamaa Yu A.R., Atlas of rough sea surface optical properties, Estonian Acad. of Sciences, Tartu (1964) (in Russian).

[8] Osadchy V. Yu., Belyakov G.N., Shifrin K.S., Lidar measurements of oil films on the sea, in: Oceanic and Atmospheric Optics, Leningrad, 1984 pp.24l-242 (in Russian).

[9] Shifrin K.S., Osadchy V.Yu., Belyakov G.N., Sensing of oil films at the sea surface using the $\mathrm{CO}_{2}$ lidar, in: Tezisy vsesoyuznogo simpoziuma po lazernomu zondirovaniyu atmosfery, Tomsk, 1978, pp. 155-159 (in Russian).

[10] Shifrin K.S., Physical Optics of Ocean Water. American Institute of Physics, New York, 1988, pp. 285.

[11] Zolotarev V.S., Kitushina 1.A., Sutovsky S.M., Optical constants of oil in the region of $0.4-15 \mu \mathrm{m}$, Okeanologiya 7 (6) (1977) 